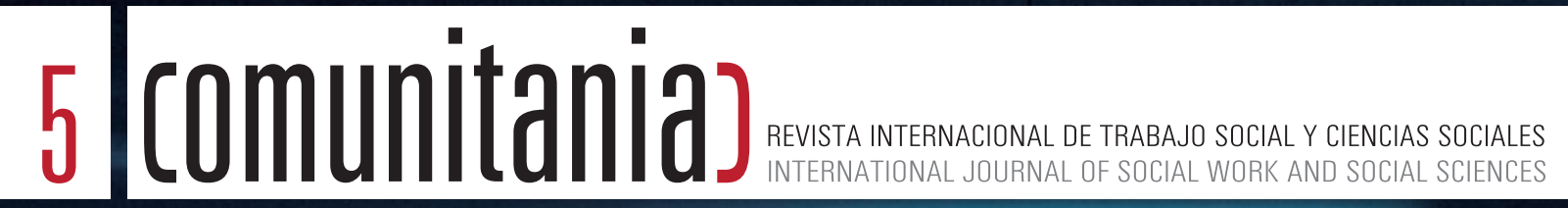

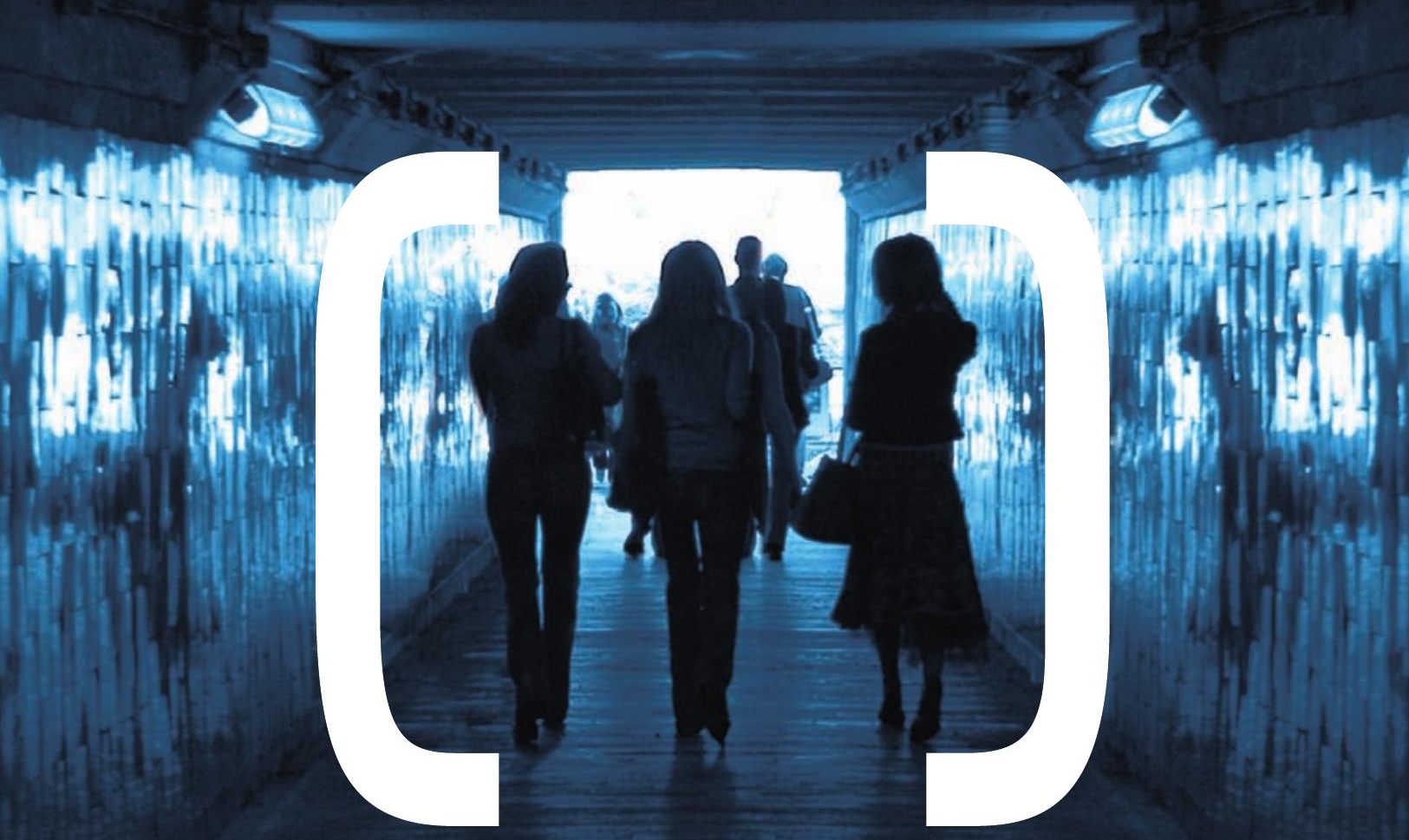

EGUZKI URTEAGA | RODRIGO ANDRÉS | ÁNGELES MARTíNEZ | Ma INMACULADA LÓPEZ | ALEJANDRO CABELLO MARÍA PAZ GARCÍA-LONGORIA | REYNA LIZETH VÁZZUEZ | ARNULFO SÁNCHEZ | EVA SOTOMAYOR | YOLANDA DE LA FUENTE MARTA GARCÍA | Ma LUISA GRANDE | TOMÁS ALBERICH | KARLA SÁENZ | DELIA TÉLLEZ | ANTONIO GUTIÉRREZZ 


\title{
La actuación de los jueces estatales como árbitros privados: un problema de orden público \\ State Judge's acting as private arbittrators: a public policy problem
}

\author{
Arnulfo Sánchez García* \\ * Universidad Autónoma de Nuevo León. arnulfosanchezgarcia@hotmail.com
}

\begin{abstract}
Abstrac:
State Judge's acting as arbitrators has been a topic of inquiry that has remained undetected by the doctrine. This is due principally to two main reasons; the first reason is that it has been a conduct considered unlikely to this moment. Secondly, negative legal effects can be foreseen. However, this acquires relevance because an arbitral procedure with these characteristics happened in Mexico. The topic is addressed in the present article with the main goal of establishing well-supported bases that allows us to consider this activity as contrary, or incompatible with the public policy. This is a matter of great importance because it allows us to establish a principle consisting in that any arbitral resolution rendered by a state judge must be considered a cause of nullity.
\end{abstract}

Keywords: Judicial function, arbitration, public policy, arbitral award.

\section{Resumen:}

La actuación de los jueces estatales en calidad de árbitros ha sido un tema de estudio obviado por la doctrina. Existen dos razones principales para ello; la primera consiste en que se trata de una conducta que hasta el momento ha sido considerada improbable. En segundo término, porque ese desempeño previsiblemente puede causar efectos antijurídicos. Sin embargo, la cuestión cobra interés después de que recientemente se suscitó un procedimiento arbitral con esa característica en México. En el presente artículo se hace aborda el tema con el objeto de establecer bases bien sustentadas que permitan considerar esa actividad como contraria al orden público. La cuestión es de trascendencia porque permite establecer un principio consistente en que una resolución arbitral dictada por un juez estatal incurre en la causal de nulidad del laudo arbitral.

Palabras clave: Función jurisdiccional, arbitraje, orden público, laudo arbitral. 


\section{Article info:}

Received: 01/09/2012 / Received in revised form: 05/02/2012

Aceppted: 10/12/2012 / Published online: 20/02/2013

DOI: http://dx.doi.org/10.5944/comunitania.5.7

\section{Introducción}

El arbitraje privado es un sistema heterocompositivo de resolución de controversias con alto grado de aceptación en la esfera internacional (Gonzalo, 2011), pero también su utilización en el ámbito doméstico es cada vez más recurrente. La buena predisposición y conciencia profesional para el uso del arbitraje en México se ha visto incrementada por varios factores como la nueva tutela Constitucional de los métodos alternos de solución de conflictos (MASC) y la inclusión de la disciplina en los planes de enseñanza de distintas carreras y universidades (Gorjón y Steele, 2008).

La cuestión de estudio en el presente artículos urge de lo acontecido en un reciente caso arbitral, cuya tramitación tuvo como sede la ciudad $W$ perteneciente a la Entidad Federativa $X$, de la República Mexicana. La composición de la litis se dio entre una empresa denominada $A /$ representada por el señor $C$ como parte demandante, y como partes demandadas una sociedad extranjera denominada $A A$ representada por el señor $\mathrm{S}$, así como una institución bancaria nacional denominada $B$. Es conveniente señalar que las demandadas eran parte en un fideicomiso: $A A$ era fideicomisario y $\mathrm{B}$ fiduciaria, el fideicomitente era otra institución bancaria $B A$, la cual había transmitido de forma irrevocable la propiedad de un bien inmueble dedicado a la actividad hotelera.

El objeto del fideicomiso fue permitir a la empresa $A A$ el uso y aprovechamiento del patrimonio de la fiduciaria. Es por eso que una de las responsabilidades del $A A$ era realizar por su cuenta la defensa del patrimonio del fideicomiso.

En la estructuración del fideicomiso se estableció que el fiduciario tenía como obligación realizar todos los actos jurídicos que $A A$ le indicara sin responsabilidad derivada de la ejecución de dichos actos. Fue el caso que, el inmueble se vio afectado por obras realizadas en un predio contiguo por una empresa denominada $D P$, por lo cual, en base a una instrucción hecha a la fiduciaria por el señor $S$-representante $\operatorname{de} A A$ - otorgó poder a un tercero llamado Señor $E$ para realizar actos de administración -con facultades para comprometerse en árbitros-, y para pleitos y cobranzas, con la finalidad de realizar la defensa del patrimonio del fideicomiso. Además, se autorizó al señor $E$ para contratar los servicios de expertos para ese efecto.

Las contratación de dichos expertos se hizo mediante un convenio celebrado entre el señor $E$ en representación de $A A$ y el señor $C$ representante de una empresa extranjera denominada $A l$. Dicho pacto tenía como objeto principal la prestación de 
servicios consistentes en la defensa del patrimonio del fideicomiso. En el mencionado contrato se incluyó cláusula arbitral para acudir al arbitraje en caso de presentarse conflicto en base a la relación contractual entre $A /$ y $A A$.

Una vez suscitada la diferencia respecto del cumplimiento del contrato se acudió a un procedimiento de arbitraje, donde las partes de común acuerdo designaron como árbitro único a un magistrado en funciones del Tribunal Supremo de Justicia de la Entidad Federativa $X$ para conocer de la controversia.

La aceptación del encargo por parte del árbitro fue hecha con la condición de que el desempeño de la función se haría de forma honorífica, es decir, sin recibir ninguna clase de retribución económica, así como que los trabajos se harían en horarios que no interviniesen con las ocupaciones propias de la magistratura. El arbitraje se desarrolló hasta su finalización y se dictó el laudo definitivo correspondiente, donde se condenó al $A A$ al pago de una serie de prestaciones.

El presente estudio tiene como objetivo determinar las incidencias del actuar de un juez o magistrado, cuando se desempeña como árbitro privado, sobre la eficacia del laudo definitivo que se dicte en el procedimiento arbitral.

En base a la situación planteada cabe preguntarse ¿un laudo arbitral dictado por un juez en funciones atenta contra el orden público?. Esto nos conecta con una segunda pregunta ¿Los laudos arbitrales dictados por jueces estatales son anulables o inejecutables? Para contestar esas preguntas debe partirse de la hipótesis consistente en que el juez, al estar investido de un poder público para dirimir controversias, se encuentra impedido para hacerlo de forma privada y por tal circunstancia el laudo que dicte será anulable.

Para hacer un adecuado tratamiento del tema se ha adoptando un enfoque cualitativo mediante el cual se pueda llegar a resultados concretos. El trabajo comienzacon la elaboración de un proceso deductivo donde ha quedado expuesta, de forma general, la función de la judicatura y su importancia en el sistema social como cuestión de interés público, así como las cualidades que deben confluir en la persona que ejerce la función jurisdiccional estatal. A la par, se ha analizado de forma particular la indisolubilidad entre la magistratura y la persona que la ejerce, por lo menos, cuando el magistrado realiza funciones de impartición de justicia arbitral, las cuales si bien tienen naturaleza privada dotan al laudo de fuerza vinculante cual sentencia judicial. Lo anterior fue útil para abordar la función arbitral como actividad subsidiaria de la judicatura en la impartición de justicia a través de laudos vinculantes de acuerdo a las reglas inherentes a la institución arbitral.

Luego, ha resultado importante abordar el principio de independencia de los árbitros y su vulneración por la participación del juez como conductor y resolutor del procedimiento arbitral, ello a modo de preámbulo para determinar la incom- 
patibilidad del carácter de juez y árbitro en un solo individuo. Una vez concluido lo anterior, se estuvo en posibilidad de determinar la actuación del juez-arbitro como una violación al orden público y, por ende, como causal de nulidad del laudo arbitral.

Al respecto, Chiovenda ha señalado que los jueces no deben desempeñarse como árbitros, sin embargo, su señalamiento obedece a una prohibición legal dentro del sistema jurídico italiano (Chiovenda, 2000). En el presente artículo fue menester atender la circunstancia del sistema legal mexicano. Con lo anterior, se estuvo en aptitud de inducir un principio general que determina que los laudos arbitrales dictados por jueces en funciones son susceptibles de anulación o de denegación de su ejecución por vulnerar el orden público.

\section{Visión tradicional del juez y su función}

El ministro Guillermo I. Ortiz Mayagoitia (Ortiz 2000) en un discurso pronunciado en el salón de sesiones del Tribunal Pleno de la Suprema Corte de Justicia de la Nación, el 19 de septiembre del año 2000, señalaba "Así, entendemos la protesta al cargo [de magistrado] como un acto por el cual no sólo se asume una función pública de primer orden, sino que entraña la adopción de una conducta personal que, sin importar tiempos ni espacios, resulte profesional, honrosa, probada, comprometida. Lo anterior de suerte tal que la dignidad del encargo esté presente en todos y cada uno de los actos del funcionario; inclusive en aquellos de carácter privado, pues sólo así se dignifica la persona y se adquiere la actividad moral para juzgar".

Tomando como punto de partida tales principios deontológicos, se puede afirmar que es en la magistratura donde recae el ejercicio de la función jurisdiccional del Estado, actividad llevada a cabo, en última instancia, por personas.Ello implica, según explica Calamandrei, el ejercicio de determinadas sumas de atribuciones legales Ilamadas "Oficios Judiciales". A su vez, la realización de esas facultades, vistas como esfera de poderes y deberes objetivamente preestablecidos, corresponden, pues, desde el punto de vista subjetivo, constituyendo de forma acabada la integración -pluripersonal- de los órganos jurisdiccionales (Calamandrei, 1996).

De ahí que, el ejercicio de la jurisdicción es una atribución sopesada en una investidura que se mantiene imperceptible a los sentidos hasta el momento en que es ostentada por una persona, de modo que finalmente es extrapolada de la abstracción a la realidad, al transferir de la norma a la toga dichas facultades en el momento que se hace el nombramiento. Lo anterior obliga a rechazar cualquier atisbo de divinidad o ficción en ejercicio de ese poder estatal y cabe concederle, en todo caso, una naturaleza meramente humana y, en última instancia, personal. 
Lo dicho conduce a pensar que la jurisdicción es ejercida exclusivamente por el juez. Pero si esto es así, es necesario cuestionar la necesidad de constituir un tribunal integrado por otros miembros -las otras figuras son el secretario y el oficial judicial-. Cabe, además, preguntarse si es a través de la integración de un tribunal que se ejerce la jurisdicción o esta si está es ejercida exclusivamente por el juez: la respuesta se encuentra en la figura del juzgador, pues el secretario si bien es parte del tribunal, no participa en la elaboración del fallo -visto como proceso mental de resolución (Sánchez 2012)-, sino que su misión es dejar constancia de las actuaciones judiciales dando fe de los acuerdos tomados en estas. A su vez, por acuerdo se entiende la resolución tomada por una o varias personas -jueces o magistrados- y el secretario es quien da forma escrita a esa resolución (Arellano 2003). La actividad del secretario es garantizar la representación física del fallo. Por ello, su actividad es coadyuvante al ejercicio de potestades jurisdiccionales al punto de ser denominada "poder de documentación" (Chiovenda 2000). Sin embargo, de ningún modo se traduce en actos de naturaleza resolutiva, de modo que el juez ostenta un monopolio en el ejercicio de la jurisdicción.

Lo anterior se puede demostrar al analizar la legislación del Estado de Jalisco. En esa Entidad, la Ley Orgánica del Poder Judicial, de 1 de junio de 1997¹, prevé [art. 134] que en caso de que la ausencia del secretario no pueda ser cubierta por el notificador, actuarán en su lugar dos testigos de asistencia -funcionarios del mismo órgano judicial-. Respecto de los juzgados menores y de paz se señala en el art. 116 que actuarán con testigos de asistencia, lo que demuestra que el secretario no es indispensable para que el tribunal realice su función.

Así, el ejercicio de la jurisdicción del Estado no presupone la actuación en conjunto, sino que la labor del secretario imprime en los actos de autoridad el requisito de constancia fehaciente, traducido en validez, empero, lo que si se admite, es que la investidura de un poder público que se coloca sobre una persona convierte al individuo en juez, de modo que este sea el único que despliegue el poder jurisdiccional en aquellos casos donde su actuar consista en la aplicación de la ley a un caso concreto para crear, a través de la sentencia, una norma vinculante, particular y relativa. Como bien señala Agustín Basave "Los aspectos concretos examinados por el juez, a la luz del derecho, deben resolverse. Para eso está la magistratura" (Basave, 2000).

Es por todo lo anterior que, los actos de juzgamiento no puedan ser separados del actuar del Estado cuando sean realizados por un juez o magistrado en funciones, independientemente de que el desempeño se dé en cualquier foro ${ }^{2}$.

\footnotetext{
1 La fecha corresponde al día de publicación de la ley en el Periódico Oficial del Estado, tónica que ha de seguirse en lo sucesivo cuando se citen preceptos legales.

2 Se hace referencia a que, independientemente de que el juez actúe en un foro privado, por ejemplo como árbitro en un procedimiento, sus actos no pueden ser vistos de forma separada al del actuar estatal en ejercicio del poder público.
} 


\section{La función jurisdiccional como cuestión de interés público: indisolubilidad de la magistratura y la persona}

Una sociedad sin derecho no puede ser entendida, este es un principio aceptado desde la antigüedad ubisocietas, ibiius [donde hay sociedad hay derecho]. Lo anterior, hace que la convivencia entre seres humanos, a partir de la abolición de la autotutela, requiera ser modelada por la norma para garantizar la igualdad y evitar choques violentos ante el surgimiento del conflicto. Así, el incumplimiento de los deberes que el derecho objetivo impone da lugar a consecuencias determinadas por la propia norma, de las cuales la más característica es la sanción (García, 1999). Por ello, la utilidad del derecho se vería mermada si no existiese manera de hacerlo cumplir, pues, en ese caso, la norma jurídica existente corre el riesgo de convertirse en derecho nugatorio ante la más mínima inobservancia del gobernado, de modo que su cumplimiento dependería de la voluntad espontanea.

La función jurisdiccional debe ser concebida como una actividad garante de la vida social pacífica, ya que actúa directamente sobre el conflicto con la aplicación del derecho.Tal circunstancia provoca un interés público de la composición de esas controversias, pues," el proceso tiene como finalidad dar la razón a quien la tenga", lo cual no es un interés exclusivo de las partes, sino de la sociedad entera (Carnelutti, 2000). De ahí que la prohibición de la autodefensa esté retribuida con el derecho fundamental que tiene el ciudadano a que se le administre justicia por tribunales expeditos para ello, derecho consagrado en el art. 17 de la Constitución Política de los Estados Unidos Mexicanos, de 5 de febrero de 1917.

De esa forma, la trascendencia de la actividad de magistrados y jueces hace que dicha función jurisdiccional sea considerada de máximo interés general, por lo que no puede ser ni delegada, -salvo por mandato legal, un ejemplo es la remisión al arbitraje contemplada en el art. 1.424 del Código de Comercio mexicano, de 13 de diciembre de 1.889, cuando exista convenio arbitral y las partes así lo soliciten-, ni desatendida. Lo dicho es refrendado con la prohibición constitucional a esta clase de funcionarios para desempeñar cualquier otro encargo, público o privado, remunerado o no, salvo los cargos no retribuidos en asociaciones científicas, docentes, literarias, o de beneficencia [art.101].

La mayoría de las Constituciones locales en México siguen la tónica de la federal consagrando la misma prohibición, por mencionar algunos ejemplos: La Constitución Política del Estado de Baja California, de 16 de agosto de 1953, [art. 66]. La Constitución Política del Estado de Baja California Sur, de 15 de enero de 1975 [art. 100], Constitución Política del Estado de Nuevo León, de 16 de diciembre de 1917 [art. 100], Constitución Política del Estado de Michoacán, de 14 de marzo de 1918 [art. 77], La Constitución Política del Estado de Guanajuato, de 18 de octubre de 1917 [art. 92], Constitución Política del Estado de Yucatán, de 14 de enero de 1918 [art. 68], Constitución Política del Estado de Quintana Roo, de 9 de enero de 1975 [art. 100], Consti- 
tución Política del Estado de Sonora de 16 de septiembre de 1917 [art. 123] que señala expresamente que los jueces y magistrados no podrán desempeñarse como árbitros de Derecho] ${ }^{3}$, Constitución Política del Estado de Nayarit, de 14 de marzo de 1918 [art. 90], Constitución Política del Estado de Tamaulipas, de 9 de febrero de 1921 [art. 112], señala expresamente que los jueces y magistrados no podrán desempeñarse como árbitros de Derecho ni como arbitradores], Constitución Política del Estado de Hidalgo, de 1 de octubre de 1920 [art. 100], Constitución del Estado de Tabasco, de 5 de abril de 1919 [art. 62], y la Constitución Política del Estado de Chiapas, de 13 de noviembre de 2012 [art. 56].

Sobre dicha prohibición se ha pronunciado la Suprema Corte de Justicia de la Nación, al señalar que el hecho de limitar a los jueces para desempeñarse en otra clase de empleo o encargo no contradice la garantía de libre ejercicio de la profesión u oficio. El criterio obedece a la necesidad de que no se afecten los derechos de la sociedad en general, pues frente al interés particular de desempeñarse en determinada actividad subyace el interés superior de la sociedad, la cual espera una correcta impartición de justicia (libertad de trabajo. El Artículo 66 de la Constitución política del estado libre y soberano de Baja Californía, no viola dicha garantía constitucional 2008) ${ }^{4}$. Ahora bien, el hecho de que la prohibición no esté señalada en términos idénticos, o tan concluyentes,en todas las Constituciones de las Entidades Federativas no desvirtúa el interés general sobre la función jurisdiccional y subsiste el indicador que revela una característica consistente en que a partir del nombramiento de juez, y mientras éste subsista, serán indisolubles la investidura judicial y la persona que la ostenta, pues de otro modo carecería de sentido la prohibición para que el funcionario dedique su tiempo libre al ejercicio de la profesión jurídica en cualquiera de sus variantes.

\section{La competencia arbitral en sustitución emergente de la actividad jurisdiccional de los jueces: la falacia del juez-árbitro}

De explorado derecho resulta el origen de los poderes del árbitro, por lo que su estudio cobra cada vez menos importancia (Fernández, 2008). Por ello, la referencia sobre el tema ha de ser somera, en todo caso, como antesala para abordar más adelante la incompatibilidad de la calidad de juez y árbitro en una misma persona. Así,

\footnotetext{
3 Es importante aclarar que si bien tal dispositivo legal prohíbe el desempeño de los jueces como árbitros de derecho, lo cierto es que no autoriza de forma expresa a que magistrados o jueces se desempeñen en otro tipo de arbitrajes, como por ejemplo aquellos que se resuelven en equidad $y$, tomando en cuenta el principio general de derecho que indica que a la autoridad le está prohibido todo lo que no le está permitido, prima facie resulta difícil admitir una posible facultad implícita que autorice el desempeño como árbitros ex a quo et bono.

4 Para una fácil localización de la tesis jurisprudencial citada véase [TA]; 9a. Época; 2a. Sala; S.J.F. y su Gaceta; Tomo XXVIII, Septiembre de 2008. p. 274.
} 
se puede decir que la naturaleza del arbitraje ha sido expuesta, de un lado, por la postura contractualista, luego por la procesalista, encontrando finalmente una respuesta ecléctica que explica un origen contractual, transformándose, posteriormente, en procesal a través de los efectos que le concede la ley (Merino y Chillón, 2006).

La necesidad de tocar el tema se suscita porque, según la óptica del presente trabajo, el problema real de la designación del árbitro por las partes consiste en que ese acto se perfecciona con la aceptación del cargo. Así, la discusión debe girar en torno a las implicaciones jurídicas suscitadas a partir de la aceptación del juez-árbitro.

¿Es posible que un juez dotado del poder del Estado pueda sustraer sus actos -de juzgamiento- de la naturaleza jurisdiccional -pública- por el solo hecho de aceptar la voluntad de las partes?. La respuesta es negativa. Admitir tal circunstancia equivaldría a aceptar que el cumplimiento del mandato constitucional de hacer justicia, siempre que el justiciable ejerza el derecho de acción, es renunciable o que su cumplimiento está al arbitrio del juez, lo cual es inaceptable en todos los sistemas jurídicos modernos.

De esa manera, atendiendo la imposibilidad de la disolución de la persona y la magistratura por lo menos cuando se emiten fallos vinculantes-, la confluencia del carácter de juez y árbitro en un solo individuo tendrá como resultado final una actividad quimérica donde, en principio, se reproducenen un solo acto de juzgamiento los efectos -cosa juzgada y a la ejecutabilidad-que la ley concede a las sentencias judiciales y a los laudos arbitrales, respectivamente, como presupuestos de eficacia.

Tal circunstancia, lejos de antojarse como una situación de refuerzo al laudo, se presenta como una redundancia inentendible e innecesaria para el derecho por los efectos que produce. Esto es porque, ese sólo hecho hace que a través de un fallo único se surtan efectos idénticos en su consecuencia, pero dispares dado su origen $\mathrm{y}$, por tal, inconfluibles en un solo acto resolutivo. En otras palabras; mientras que el laudo puede obtener el grado de cosa juzgada y ser ejecutable porque la ley así lo determina tomando como base de la voluntad de las partes, la actividad del juez tiene un sustento constitucional. Por ello, no se puede entender que en un solo acto resolutivo confluyan al mismo tiempo los efectos de cosa juzgada y ejecutabilidad que la ley confiere a fallos dictados en ámbitos equivalentes, pero finalmente equidistantes. Tal circunstancia crearía una resolución siamesa paralizada por el obrar en su interior de fuerzas jurídicas iguales, pero paralelas y por tal irreconciliables. Lo anterior permite adoptar un principio básico: una resolución puede ser laudo, o sentencia, pero no ambas en una sola, pues colisionarían en un mismo acto dos instituciones que son de diferente naturaleza.

Lo anterior cobra mayor sentido cuando se repara en el hecho de que la ley concede al laudo fuerza ejecutiva una vez que ha superado el auscultamiento judicial, precisamente por la ausencia de las facultades de imperio del Estado en el árbitro. 
Por su parte, las sentencias judiciales cobran esa característica por el sólo hecho de cumplir los requisitos que la ley les exige para que causen ejecutoria [por ejemplo los arts. 354, 355, 356, 357, 407 Frac. I, y 614 del Código Federal de procedimientos Civiles, de 24 de febrero de 1943]. Para el caso, la resolución brindada por un juez-árbitro se quedaría en un punto medio donde forzosamente se verían confluir efectos que la ley separa y distingue para un caso y otro, y por tal, inconfluibles, aun a pesar de tener los mismos efectos cuando son verificados en sus respectivos ámbitos. De modo que la reacción del derecho frente a esa resolución sería errática y confusa, pues sería en extremo difícil la determinación del régimen de ejecución aplicable -el correspondiente a las sentencias judiciales o el aplicable a los laudos arbitrales-.

\section{La vulneración del principio de independencia de los árbitros por la actuación del juez-arbitro}

La independencia de los árbitros consiste en estar desprovisto de todo vínculo con las partes, los otros árbitros, e incluso de la institución arbitral (Lepervanche, 2011). En México, la Constitución en el art. 17 consagra el derecho de acceso a la justicia a través de los tribunales que estarán expeditos para ello. En ese sentido, el juez tiene un compromiso con la sociedad en general, pues, si bien es cierto que la jurisdicción del Estado se activa solamente por el ejercicio de la acción, también lo es que la Carta Magna establece un vínculo estable y permanente entre el juzgador y cualquier miembro de la sociedad, traducido en el hecho de que jueces y magistrados deben garantizar -siempre que acudan a él las partes- el acceso del ciudadano a la justicia mediante una actividad pública denominada proceso judicial.

Entonces, el problema de independencia se suscita porque el magistrado que tiene un compromiso permanente por mandato constitucional y preadquirido con cualquier miembro de la sociedad, al momento de actuar en el ámbito privado como árbitro realizando actos de equivalente jurisdiccional altera el orden impuesto por la Constitución, porque el acto que realiza es de similar naturaleza al mandado de brindar un servicio público de administración de justicia, lo cual genera una coexistencia no autorizada por el Derecho.

Así, pues, el juez que actúa como árbitro en aras de hacer justicia incurre en un acto injusto, ya que desatiende el mandato constitucional de ejercer de forma exclusiva y bajo los límites legales el poder con el cual está investido, del que, además, no puede separarse por voluntad personal cuando emite actos de juicio vinculantes. Por lo que debe concluirse que un juez en funciones, dado el compromiso adquirido previamente con la sociedad, está impedido aceptar el nombramiento de árbitro toda vez que carece de legitimidad para juzgar en foros privados. 


\section{Incompatibilidad de la cualidad de juez y árbitro en la persona investida con la judicatura}

Arellano García señala que, desde un punto de vista formal -aquel que atiende a la actuación del Estado-, todo lo que hace el poder judicial se considera función jurisdiccional. Así, adoptando un criterio subjetivo, todo lo que haga el juez -cuando su actuar consiste en resolver la litis- será de la misma naturaleza (Arellano, 2003). Ello incide directamente en la posibilidad de que el juez desvié su actividad del ámbito públicoa rubros de equivalencia jurisdiccional dentro de un canal privado, porque, como ya se dijo, ninguna autoridad judicial puede delegar a otra corporación o persona, pública o privada, su función, dado el interés público en torno a ella salvo en los casos establecidos en la ley.

Lo anterior es, porque el juez tiene el deber fundamental de desempeñar las actividades inherentes a su función (Chiovenda 2000): conocer de las controversias que se le presenten y emitir el fallo correspondiente. Deberes irrenunciables dada la utilidad pública que aportan. De ahí la prohibición constitucional ${ }^{5}$ [art. 101] para desempeñar cualquier otro cargo o empleo, salvo los tasados por la misma Norma Suprema.

En ese sentido, el hecho de que un magistrado actúe como árbitro privado se traduce en la renuncia expresa de las facultades que originalmente le corresponden, pues mientras que los actos del magistrado corresponden al Estado, los realizados por el árbitro corresponden al ámbito privado. Entonces, la exclusividad que impone la constitución a la persona del juez para desempeñar solamente la función judicial impide que el sujeto pueda determinar libremente la naturaleza de sus actos como parte, o no, de la manifestación del poder del Estado. En otras palabras, la ley determina el encuadramiento de los actos del juez dentro de lo público, y en eso nada tiene que ver la voluntad o inclinaciones del funcionario judicial.

La aceptación del magistrado al cargo de árbitro atenta directamente contra confianza que confiere su investidura, toda vez que con esa conducta incurre en una especie de privatización su actividad. La mera propuesta de las partes para que un juez se desempeñe como árbitro no es censurable jurídicamente, pues se trata de una conducta no prohibida por la ley. Sin embargo, es inentendible para el derecho cuando tal acto es consentido por el servidor público, ya que encierra una renuncia flagrante al desempeño de su actividad -en la esfera pública- característica esencial de su actuar como parte del Estado.

Hasta el momento no se tiene noticia de disposición legal en México que autorice expresamente a jueces y magistrados para actuar como árbitros privados. Al respecto, la Suprema Corte de Justicia ha sostenido que las autoridades solamente tie-

5 Constitución Política de los Estados Unidos Mexicanos, de 5 de Febrero de 1917. 
nen las atribuciones que la ley les confiere, mismas que no podrán ser prorrogadas por las partes. Por ello, la resolución de una controversia en arbitraje por parte de un servidor público -haciendo referencia al gobernador de un Estado- no puede ser considerada como obra de autoridad (trabajo, incapacidad constitucional de los gobernadores, como arbitros en materia de..., 1939) ${ }^{6}$. Sin embargo, la actividad fundamental del poder ejecutivo no consiste en la resolución de controversias jurídicas, por lo que su actuación en calidad de árbitro no puede ser confundida con su actividad normal. Sin embargo, la actividad del juez no sigue la misma suerte. Tomando en cuenta el mandato constitucional que per se obliga al juez a ejercer la jurisdicción -en los casos de procedencia- y la existencia simultanea de una cláusula arbitral capaz de excluir esa jurisdicción, el resultado es una confusión entre el deber jurisdiccional y la disponibilidad de la controversia privada por las partes al momento en que ese juez-arbitro emite el fallo vinculante. Así, la actualización de dos figuras que igualmente hacen justicia, el juez por mandato de ley y el árbitro por mandado volitivo, hace que se produzca una colisión entre dos actividades que se excluyen entre sí, lo cual neutraliza la actividad para dejar sin efecto el instrumento resolutivo.

En conclusión, la cláusula arbitral excluye la jurisdicción del juez al servir como fundamento para la excepción de incompetencia (Cremades, 1975). De ese modo, la calidad de juez es suficiente para excluir la posibilidad de que en el mismo individuo confluya la calidad de árbitro, porque ostentar dos investiduras que cumplen la misma función -y que adicionalmente una excluye a la otra- es redundante, inentendible para el Derecho y, por tal, incompatible. De esa manera el ejercicio de la jurisdicción a partir de la confluencia de dos competencias: la judicial y la arbitral en una misma persona es un contrasentido que resulta desafortunado a los ojos del ordenamiento jurídico.

\section{La intervención de los jueces estatales, en calidad de árbitros, como causal de nulidad o inejecución del laudo por la vulneración del orden público}

Un laudo que atenta contra el orden público debe ser declarado invalido de conformidad con el art. 1452.II in fine del Código de Comercio mexicano, de 13 de diciembre de 1889, o inejecutable según el art. art. V.2.b de la Convención sobre el Reconocimiento y Ejecución de las Sentencias Arbitrales Extranjeras, hecha en Nueva York en 1958. Coincidimos con Gonzalo Quiroga en la dificultad de determinar de forma clara, concisa y concluyente lo que debe entenderse por orden público (Gonzalo 2003). Al respecto, el Tercer Tribunal Colegiado en Materia Civil del Tercer Circuito, refiriéndose a la aplicabilidad de los preceptos antes citado, ha deter-

\footnotetext{
6 Para una fácil localización de la tesis jurisprudencial citada véase [TA]; 5a. Época; 4a. Sala; S.J.F.; Tomo LXII. p. 1148.
} 
minado que "la noción de orden público tiene como marco de referencia, nacional e internacional, la institución de arbitraje a la que no puede frustrar, alterar u obstaculizar en su misión y exige una precisión en cuanto a su definición, alcance y contenido, porque sólo de esa manera puede esclarecerse en qué casos y bajo qué condiciones resulta pertinente su aplicación"(orden público. Principio proarbitraje y reconocimiento de la autonomía de la voluntad para ponderar la nulidad del laudo arbitral interpretación del artículo $\mathrm{V}$, punto 2 , inciso $\mathrm{B}$ ), de la convención sobre el reconocimiento y ejecución de sentencias... 2010) ${ }^{7}$. Por ello, el intento estará enfocado en determinar que la actuación del juez, en calidad de árbitro, atenta en contra de reglas irrenunciables por el Estado en su faceta reguladora de las decisiones arbitrales.

El sólo hecho de que las partes designen a un juez en funciones como árbitro privado no encierra violación alguna a los límites de la autonomía de la voluntad, dado que esa designación no surte efectos jurídicos inmediatos y su relevancia en el derecho no sobrepasa los límites de una mera expectativa jurídica mientras que no obra aceptación por el juez-árbitro. Esto es porque la naturaleza contractual del convenio arbitral hace necesaria la aceptación de árbitro (González, 2008). Así, hasta el momento en que se suscita la controversia y el juez-árbitro acepta el encargo, el convenio arbitral comienza a desplegar plenamente sus efectos jurídicos y por consecuencia se inhibe la competencia que permite al juez desempeñar su jurisdicción. Hasta ese instante, pues, se puede hablar de actos perceptibles en la realidad jurídica, donde el juez acepta la inhibición de su propia competencia para ejercerla de forma privada, lo cual, si bien, no puede ser separado de la conducta propositiva de las partes. El juez en su actuar ignora el mandato de exclusividad su desempeño profesional al ámbito judicial que dispone la Ley [art. 101 Const.], por lo que su conducta se vuelve cuestionable ante la inobservancia del principio in obscuris veldubiis id est sequendum, quod legibus non sitcontrarium [en las cosas oscuras y dudosas debe seguirse lo que no sea contrario a las leyes].

Antes quedó justificado el interés público de la actividad jurisdiccional. Al respecto, la jurisprudencia mexicana ha entendido que la noción de interés público se traduce en la existencia de normas imperativas que por su naturaleza no pueden ser derogadas por los particulares, ya que defienden el interés de estos pero también el del Estado, por lo cual, es válido atribuir ese carácter a las normas que disponen, regulan y limitan la actividad jurisdiccional (orden público. Su coción y contenido en la materia civil 2010).

Antes se dijo que el juez al aceptar la designación de árbitro y dictar el laudo correspondiente desplaza el ejercicio de su jurisdicción a un plano privado, igno-

\footnotetext{
7 Para una fácil localización de la tesis jurisprudencial citada véase [TA]; 9a. Época; T.C.C.; S.J.F. y su Gaceta; Tomo XXXIII, Mayo de 2011. p. 1241.
} 
rando de esa forma el precepto constitucional que le impone la obligación de garantizar la existencia de tribunales expeditos para hacer justicia a los justiciables [art. 17]. Ahora bien, también se ha señalado que esa disposición, al ser de interés general, es irrenunciable e intransferible -por el juez- dada la prohibición de la autordefensa, es decir, si el Estado prohíbe dicha autotutela, también debe garantizar un mecanismo compensatorio para acceder a la justicia. Tal circunstancia hace que la disposición constitucional que comento sea una norma imperativa indisponible para el juez, pues, además, se configura como una norma de orden público toda vez que la administración de justicia es una actividad fundamental de equilibrio social en todo orden jurídico. Lo anterior hace concluir que el actuar del juez como árbitro, aunque exista previo consentimiento de las partes, viola normas imperativas de orden público.

Además, según el Código Civil Federal, de 31 de agosto de 1928 [art. 6], la voluntad de las partes no puede eximir la inobservancia de la ley cuando afecte al interés público o los intereses de terceros. En el caso que nos ocupa, la aceptación del juez es el acto final que pone en marcha los efectos jurídicos de la cláusula arbitral propuesta por las partes. Pero eso no desvanece el hecho de que el efecto es causado por la implicación previa de la voluntad de las partes, sobre todo si se atiende al principio privatorum conventio juri publico non derogant [las convenciones de particulares no pueden derogar el derecho público] y en este caso la conducta de las partes no es ajena a la aceptación del juez del nombramiento de árbitro, lo cual, en primera instancia, genera la consecuencia, isdamnumdat, quijubetdari [causa el daño el que lo manda]. De esa forma, el art. 6 del Código Civil Federal debe ser entendido en el sentido de que ni las partes, ni terceros por voluntad de estas, quedan exentos del cumplimiento de la norma imperativa.

En ese sentido, jurisprudencialmente se ha determinado que "el orden público constituye un límite en el uso y goce de los derechos fundamentales de los particulares. Se trata de una limitación genérica impuesta desde la constitución pero que también atañe a los que derivan de los derechos y libertades privadas y públicas de otros particulares con lo que eventualmente se entra en contacto" (orden público. Es el límite a la libertad contractual derivado de los valores más importantes que recoge el orden jurídico y requiere de la pnderación judicial 2010). Si bien eso es cierto, también lo es que, los actos de las partes tendientes a nombrar al juez como árbitro privado sólo tendrán relevancia social y jurídica hasta la aceptación de este. Lo anterior, indica que la violación del orden público se dará con la verificación real de una conducta compuesta tanto por la conducta de las partes -que induce la violación-y la aceptación del juez-árbitro que es el acto que realmente define la violación. En ese sentido los laudos que atentan contra el orden público incurren nulidad o inejecución en todas las jurisdicciones (Tweeddale y Tweeddale, 2007). 


\section{Conclusiones}

Una vez elaborada la panorámica jurídica sobre el juez y su función se puede concluir que se trata de una actividad que sirve para regular la convivencia pacífica y ordenada en sociedad, por lo cual es considerada de interés público. Lo anterior, es un precedente que permite afirmar la indisolubilidad entre la investidura judicial y la persona que la ostenta, porque la sociedad espera en todo momento una impartición de justicia adecuada y correcta. De ahí la prohibición a jueces y magistrados para desempeñarse en otros ámbitos laborales, salvo las excepciones expresamente contenidas en la Ley. También se pudo determinar que se trata de una norma imperativa de orden público y que su inobservancia conlleva la nulidad de los actos ejecutados.

Ahora bien, dada la naturaleza subsidiaria de la actividad que realiza el árbitro respecto de la función judicial, así como la respectiva regulación legal de la función arbitral y la judicial, además de los efectos jurídicos y regímenes de ejecución que la ley contempla respecto de las sentencias judiciales y los laudos arbitrales, se ha determinado que la confluencia del juez y árbitro en un solo individuo daría como resultado una sentencia definitiva de carácter híbrido con consecuencias jurídicas inconfluibles en una misma resolución. Con ello, se hace referencia a la reproducción de la cosa juzgada y la ejecutabilidad de dos sistemas de justicia diferentes en un solo instrumento resolutivo. Por tal motivo, con la existencia de esta clase de laudos se origina un esquema redundante e inentendible para el derecho que, en todo caso, sobrecargaría de efectos jurídicos la resolución final con consecuencias funestas, pues el ordenamiento no respondería ante el instrumento resolutivo por la imposibilidad de atribuirle una naturaleza jurídica bien definida.

Por lo anterior, y tomando en cuenta que la aceptación de un juez para actuar como árbitro atenta contra el principio de independencia privándolo de legitimidad para juzgar en esos casos, se pudo concluir que es incompatible la calidad de juez y árbitro en una misma persona, pues implica una vulneración al orden público consistente en la desviación de la función judicial que constitucionalmente tiene que desempeñar de forma exclusiva. Así, se genera un principio consistente en que todos los laudos dictados por un juez en funciones incurren en las causales de nulidad y denegación al reconocimiento y ejecución del laudo arbitral consistente en la vulneración al orden público, contenidas, respectivamente, en el Código de Comercio mexicano y en la Convención de Nueva York de 1958.

\section{Trabajos citados}

Arellano, C.2003. Manual del abogado. México: Porrúa.

Basave, A. 2000. Estructura y sentido de la judicatura: Funcion y misión del juez. San Nicolas de los Garza: Universidad Autónoma de Nuevo León. 
Calamandrei, P. 1996. Derecho Procesal Civil. México: Editorial Pedagógica Iberoamericana.

Carnelutti, F. 2000. Instituciones de derecho procesal civil. México: Oxford.

Cremades, B. 1975. Panoramica española del arbitraje comercial internacional. Madrid: Marcial Pons.

Chiovenda, G. 2000. Curso de derecho procesal civil. México: Oxford.

Fernández, J.C. 2008. Tratado del arbitraje comercial en América Latina. Madrid: lustel.

García, E. 1999. Introducción al estudio del Derecho. México: Porrúa.

González, F. 2008. El árbitro. México: Porrúa.

Gonzalo, M. 2011. "Métodos alternos: Una justicia más progresista y universalizada". Pp. 41-67 en Métodos alternos de solución de conflictos: Herramientas de paz y modernización de la justicia, editado por M. Gonzalo, F. J. Gorjón y A. Sánchez. Madrid: Dykinson.

- . 2003. Orden público internacional en el marco de la globalizacion comercial: Arbitrabilidad y Derecho aplicable al fondo de la controversia internacional. Madrid: Dykinson.

Gorjón, F. J. y J. G. Steele. Métodos alternativos de solución de conflictos. México: Oxford.

Lepervanche, C. 2011. "Algunos apuntes sobre la independencia e imparcialidad de los árbitros en el arbitraje comercial". Revista del Club Español de Arbitraje 31.

Merino, J. F. y J. M. Chillón. 2006. Tratado de Derecho Arbitral. Navarra: Aranzadi.

México. 1939. "trabajo, incapacidad constitucional de los gobernadores, como arbitros en materia de". 1604/39 4 a Sala, Tesis aislada, Suprema Corte de Justicial de la Nación, 23 de octubre de 1939.

México. 2008. "libertad de trabajo. El artículo 66 de la constitución política del estado libre y soberano de Baja California, no viola dicha garantía constitucional". 204/2008 $2^{\text {a }}$ sala, Tesis aislada, Suprema Corte de Justicia de la Nación, 13 de agosto de 2008.

México. 2010. "orden público. Es el límite a la libertad contractual derivado de los valores más importantes que recoge el orden jurídico y requeire de la ponderación judicial". 195/2010 Tesis Aislada, Tecer Tribunal Colegiado en Materia Civil del Primer Circuito, 7 de octubre de 2010.

México. 2010. "orden público. Su noción y contenido en la materia civil".195/2010 Tesis aislada, Tercer Tribunal Colegiado en Materia civil del Primer Circuito, 7 de octubre de 2010.

México. 2010. "orden público. Principio proarbitraje y reconocimiento de la autonomía de la voluntad para pondearar la nulidad del laudo arbitral (interpretación del artículo $V$, punto 2, inciso B), de la convención sobre el reconocimiento y ejecución de sentencias". 195/2010 Tesis aislada, Tercer Tribunal Colegiado en Materia civil del Primer Circuito, 7 de octubre de 2010.

Ortiz, G. I. 2000. El compromiso de ser juez. México: Poder Judicial de la Federación.

Sánchez, A. 2012. La eficacia de los métodos alternos de solución de conflictos en España y México: Perspectiva integral de los acuerdos de mediación y los laudos arbitrales.Universidad Rey Juan Carlos: Tesis Doctoral.

Tweeddale, A. and K. Tweeddale. 2007. Arbitration commercial disputes. Great Britain: Oxford University Press. 


\section{comunitania}

REVISTA INTERNACIONAL DE TRABAJO SOCIAL Y CIENCIAS SOCIALES

REVISTA INTERNACIONAL DE TRABAJO SOCIAL Y CIENCIAS SOCIALES
INTERNATIONAL. JOURNAL OF SOCIAL WORK AND SOCIAL SCIENCES

\section{ARTICULOS/ARTICLES}

Estado de bienestar e inversión social en Europa / Welfare State and Social Invesment in Europe

Eguzki Urteaga

Reflexiones sobre el Espacio Público y Participación en las Políticas de Vivienda en Santiago de Chile. Hacia una Práctica Comunitaria / Reflections, on public space and participation in public housinng policies in Santiago de Chile. Towards a community practice

Rodrigo Andrés Mardones

El déficit de transversalidad de género en la Unión Europea / Gender transversality deficit in the European Union

Ángeles Martínez Boyé

Págs 37-60

La construcción de la masculinidad y su relación con la violencia de género / The development of masculinity and relationship to gender violence

$\mathrm{M}^{a}$ Inmaculada López Núñez

Elementos del proceso de mediación que favorecen a su implementación como política social / Elements of the mediation process that benefits implementation as social policy

Paris Alejandro Cabello Tijerina

La mediación escolar y las habilidades sociales en los estudiantes de educación secundaría. Un estudio en institutos de la región de Murcia / School mediation and social skills students in secondary education. A study in institutes of Murcia

María Paz García-Longoria Serrano y Reyna Lizeth Vázquez Gutiérrez

La actuación de los jueces estatales como árbitros privados: un problema de orden público /

State Judge's acting as private arbitrators: a public policy problem

Arnulfo Sánchez García

Págs 137-151

Calidad en los servicios de bienestar en un contexto de crisis económica internacional / Quality in

welfare services in a context of international economic crisis

Eva Sotomayor Morales, Yolanda De la Fuente Robles, Marta García Domingo,

$\mathrm{M}^{\mathrm{a}}$ Luisa Grande Gascón y Tomás Alberich Nistal

Págs 153-179

Contexto de la equidad en los servicios de salud / Context of equity in health services in Mexico

Karla Sáenz López y Delia Téllez Castilla

Págs 181-199

Los Servicios Sociales en España, puestos a prueba por las personas inmigrantes / Social Services

in Spain, tested by inmigrants

Antonio Gutiérrez Resa

Págs 201-227

\section{RESEĨAS/REVIIEWS}

Rubén Darío Torres Kumbrián. Trabajo Social con Comunidades y Mujeres Musulmanas:

"Diagnóstico de las discriminaciones múltiples" / Social Work with Communities and Muslim

women (por Ángeles Martínez Boyé).

Págs 229-234

Manuel Herrera Gómez y José Daniel Barquero Cabrero. Redes sociales: de metáfora a paradigma /

Social Networks: from metaphor to paradigm (por Salvador Gómez García)......

Págs 235-236

Djamil Tony Kahale Carrillo, Protección a las personas en situación de dependencia / Protection of persons in situations of dependency (por Sara Pérez Martínez). 